2-1-2011

\title{
Oyster Reefs at Risk and Recommendations for Conservation, Restoration, and Management
}

\author{
Michael W. Beck \\ Robert D. Brumbaugh \\ Laura Airoldi \\ Alvar Carranza \\ Loren D. Coen
}

See next page for additional authors

Follow this and additional works at: https://scholarworks.wm.edu/vimsarticles

Part of the Terrestrial and Aquatic Ecology Commons

\section{Recommended Citation}

Beck, Michael W.; Brumbaugh, Robert D.; Airoldi, Laura; Carranza, Alvar; Coen, Loren D.; Crawford, Christine; Defeo, Omar; Edgar, Graham J.; Handcock, Boze; Kay, Matthew C.; Lenihan, Hunter S.; Luckenbach, Mark; Toropova, Caitlyn L.; Zhang, Guofan; and Guo, Ximing, Oyster Reefs at Risk and Recommendations for Conservation, Restoration, and Management (2011). BioScience, 61(2), 107-116. https://doi.org/10.1525/bio.2011.61.2.5 


\section{Authors}

Michael W. Beck, Robert D. Brumbaugh, Laura Airoldi, Alvar Carranza, Loren D. Coen, Christine Crawford, Omar Defeo, Graham J. Edgar, Boze Handcock, Matthew C. Kay, Hunter S. Lenihan, Mark Luckenbach, Caitlyn L. Toropova, Guofan Zhang, and Ximing Guo 


\title{
Oyster Reefs at Risk and
}

\section{Recommendations for Conservation, Restoration, and Management}

\author{
MICHAEL W. BECK, ROBERT D. BRUMBAUGH, LAURA AIROLDI, ALVAR CARRANZA, LOREN D. COEN, CHRISTINE \\ CRAWFORD, OMAR DEFEO, GRAHAM J. EDGAR, BOZE HANCOCK, MATTHEW C. KAY, HUNTER S. LENIHAN, MARK \\ W. LUCKENBACH, CAITLYN L. TOROPOVA, GUOFAN ZHANG, AND XIMING GUO
}

\begin{abstract}
Native oyster reefs once dominated many estuaries, ecologically and economically. Centuries of resource extraction exacerbated by coastal degradation have pushed oyster reefs to the brink of functional extinction worldwide. We examined the condition of oyster reefs across 144 bays and 44 ecoregions; our comparisons of past with present abundances indicate that more than $90 \%$ of them have been lost in bays (70\%) and ecoregions (63\%). In many bays, more than $99 \%$ of oyster reefs have been lost and are functionally extinct. Overall, we estimate that $85 \%$ of oyster reefs have been lost globally. Most of the world's remaining wild capture of native oysters (> 75\%) comes from just five ecoregions in North America, yet the condition of reefs in these ecoregions is poor at best, except in the Gulf of Mexico. We identify many cost-effective solutions for conservation, restoration, and the management of fisheries and nonnative species that could reverse these oyster losses and restore reef ecosystem services.
\end{abstract}

Keywords: shellfish, oyster reef, marine conservation, fisheries, habitat restoration

O yster reefs and beds (hereafter reefs) were once a dominant structural and ecological component of estuaries around the globe, fueling coastal economies for centuries. Oysters are ecosystem engineers; one or a few species produce reef habitat for entire ecosystems (Lenihan and Peterson 1998). They have supported civilizations for millennia, from Romans to California railroad workers (Mac-Kenzie et al. 1997a, 1997b). In 1864, 700 million European flat oysters (Ostrea edulis) were consumed in London, and nearly 120,000 workers were employed as oyster dredgers in Britain. Shell piles from historical harvests in the southwest of France contain more than 1 trillion shells apiece, underscoring both the productivity of the species and the scale of harvest (MacKenzie et al. 1997b). In the 1870s, intertidal reefs of the eastern oyster Crassostrea virginica extended for miles along the main axis of the James River in the Chesapeake Bay; by the 1940s, these reefs had largely disappeared (Woods et al. 2005). In many coastal areas, including the Texas coast, roads were paved with oyster shells (Doran 1965).

Oyster reefs are one of the few marine ecosystems for which direct estimates of condition can be calculated, because most underlying reef structures are created by just one or a few oyster species. Most estimates of the condition of marine ecosystems are indirect and are derived from the distribution of threats such as trawling, sedimentation, and pollution (e.g., Halpern et al. 2008). There have been only a few direct assessments of the condition of coastal and marine ecosystems, mainly of those that are intertidal or that exist in clear water and can be aerially assessed. Records of the abundance and catch of oysters and the distribution of the ecosystems that they create can span centuries and millennia, though usually not as continuous data sets. The condition of oyster ecosystems has been considered in part by others (e.g., Jackson et al. 2001, Kirby 2004, NRC 2004, Ruesink et al. 2005, Lotze et al. 2006, Airoldi and Beck 2007), but these estimates of condition have used data from only a limited number of bays. To expand on these efforts we synthesize quantitative data on the condition of oyster reefs in more than 140 bays, provide an overall estimate of oyster reef condition, and use this extensive information to identify areas and opportunities to improve the condition of oyster reefs at a global scale.

\section{Assessing condition}

We identified native oyster reef condition primarily as a function of oyster abundance; we calculated condition using estimates of past and present abundances from the literature. Measures of total reef area and size were occasionally available. Fishery statistics for native oysters were the most commonly available information for assessing the changes in oyster abundance and the condition of reefs, but landings data were rarely the only information used to assess condition. Ultimately, reef size is a function of the number of living oysters, and larger reefs positively influence oyster growth and survival (Lenihan and Peterson 1998, 
Lenihan 1999). Water quality also affects oysters but is less reliable as an indicator of oyster condition, as oysters can thrive well past the point at which human health concerns become an issue.

We considered the condition of native oyster reefs at two different spatial scales: bays and ecoregions. For our purposes, "bays" refers to bays, estuaries, embayments, coastal counties, and portions of coastlines (e.g., Mobile Bay, Wadden Sea, Venice Lagoon). "Bays" was the most consistently used term to describe this common ecological unit in reports of oyster science, management, and conservation. Ecoregions are regional, biogeographic units with coherence in their species and ecosystems; we used the boundaries identified by Spalding and colleagues (2007).

We established four categories of condition on the basis of comparisons of current with historical oyster abundance indicators (e.g., surveys, landings, catch per unit effort) or aerially measured reef extents: (a) less than 50\% lost (good), (b) 50\% to $89 \%$ lost (fair), (c) $90 \%$ to $99 \%$ lost (poor), and (d) more than 99\% lost (functionally extinct). We looked at records from between 20 and 130 years before present to estimate historical abundances and extents. We based the date range on the availability and reliability of the data. Interestingly, surveys from a century ago were frequently better than records from decades ago or even the present.

We used practical and conservative rules for assigning condition. When sources indicated that it was difficult to find reefs, or that no reefs remained in bays where annual catch records were high (usually $>10,000$ metric tons) but historical observations indicated that reefs had once been extensive, we estimated that more than $99 \%$ of the habitat was lost, and classified the condition as functionally extinct (Jackson 2001). Such was the case, for example, in the Wadden Sea (European Union), Narragansett Bay (United States), Southport (Australia), and Ciénaga Grande de Santa Marta (Colombia). The condition was classified as poor $(90 \%$ to $99 \%$ habitat lost) when evidence indicated that fisheries were collapsing (or collapsed) but there was evidence that reefs remained, even if long-term viability was questionable (e.g., Chesapeake Bay [United States], Bohai Bay [China]). There is abundant evidence that shellfisheries continue well past the point at which $90 \%$ of the habitat has been lost (MacKenzie et al. 1997b, Kirby 2004). We classified the reef condition as fair (50\% to 89 $\%$ habitat lost) when abundance indicators were below $50 \%$ of historical figures or records indicated greater than $50 \%$ loss in reefs and there was evidence of significant remaining reefs (e.g., Apalachicola Bay [United States], Golfo San Matías [Argentina]). We considered the condition good $(<50 \%$ lost $)$ if fisheries were only lightly to moderately exploited (or not at all exploited) and if many areas of reefs remained relative to earlier abundances (e.g., Mobile Bay [United States], Nootka Sound [Canada]). If there was any question, we discussed the data-driven estimates with fishery and habitat managers and scientists from each location. The only common debate in publications was not about the condition of the ecosystems but the cause of the decline (e.g., Kirby 2004, Ogburn et al. 2007).

We identified the condition of oyster reefs across coastal ecoregions using information from multiple bays within ecoregions and national and regional publications on the status of oyster populations (e.g., red lists) and fisheries (e.g., MacKenzie et al. 1997b, Gillespie 2009). We identified the condition of oyster reefs in an ecoregion if there were one or more references that characterized regional condition or if the condition was firmly documented in three or more bays within the ecoregion. When there were several bays in an ecoregion and no other regional sources of status information, the condition estimates were averaged for all bays in the ecoregion and rounded to the nearest integer.

\section{Oyster reef condition}

The overall condition of native oyster reefs is poor in most of the 144 bays in 40 ecoregions we evaluated (figure 1; see supplementary material table $\mathrm{S} 1$ at $h \mathrm{ttp}: / /$ conserveonline.org/ workspaces/Shellfish\%20Reefs\%20At\%20Risk/documents/ oyster-reefs-at-risk-supplementary-table). Although individual oysters are still present in most places, records of historical (past 20 to approximately 130 years) and recent abundances show that many reefs that were once common are now rare or extinct as ecosystems. Oyster reefs are at less than $10 \%$ of their prior abundance in most bays (70\%) and ecoregions (63\%). They are functionally extinct-in that they lack any significant ecosystem role and remain at less than $1 \%$ of prior abundances in many bays $(37 \%)$ and ecoregions (28\%)-particularly in North America, Australia, and Europe. Very few bays and ecoregions are rated as being in good condition (> 50\% of reefs remaining). Our results most likely underestimate losses because of the lack of historical abundance records, which particularly affects assessments in South America, temperate Asia, and South Africa.

Our estimates of reef conditions are conservative because (a) where there was question of status, we applied the higher ranking; (b) for most bays and ecoregions it was clear that abundances were usually at the lower end of their condition ranking; and (c) the estimates were usually based on only part of the historical loss, as reefs were probably more abundant before the recording of fishery catches began.

Overall, we estimate an $85 \%$ loss of oyster reef ecosystems globally (figure 1). We calculated this by using the midpoint value for each condition category of oyster reefs lost in ecoregions (e.g., 95\% of habitat lost for ecoregions in poor condition), and then averaged the loss among all ecoregions.

Prior records from many bays indicated that oyster reefs were abundant and supported large fisheries - up to hundreds of thousands of metric tons of recorded catchbut those reefs and fisheries are now greatly reduced or gone (MacKenzie et al. 1997a, 1997b, Kirby 2004, NRC 2004, Ruesink et al. 2005, Lotze et al. 2006). We found 


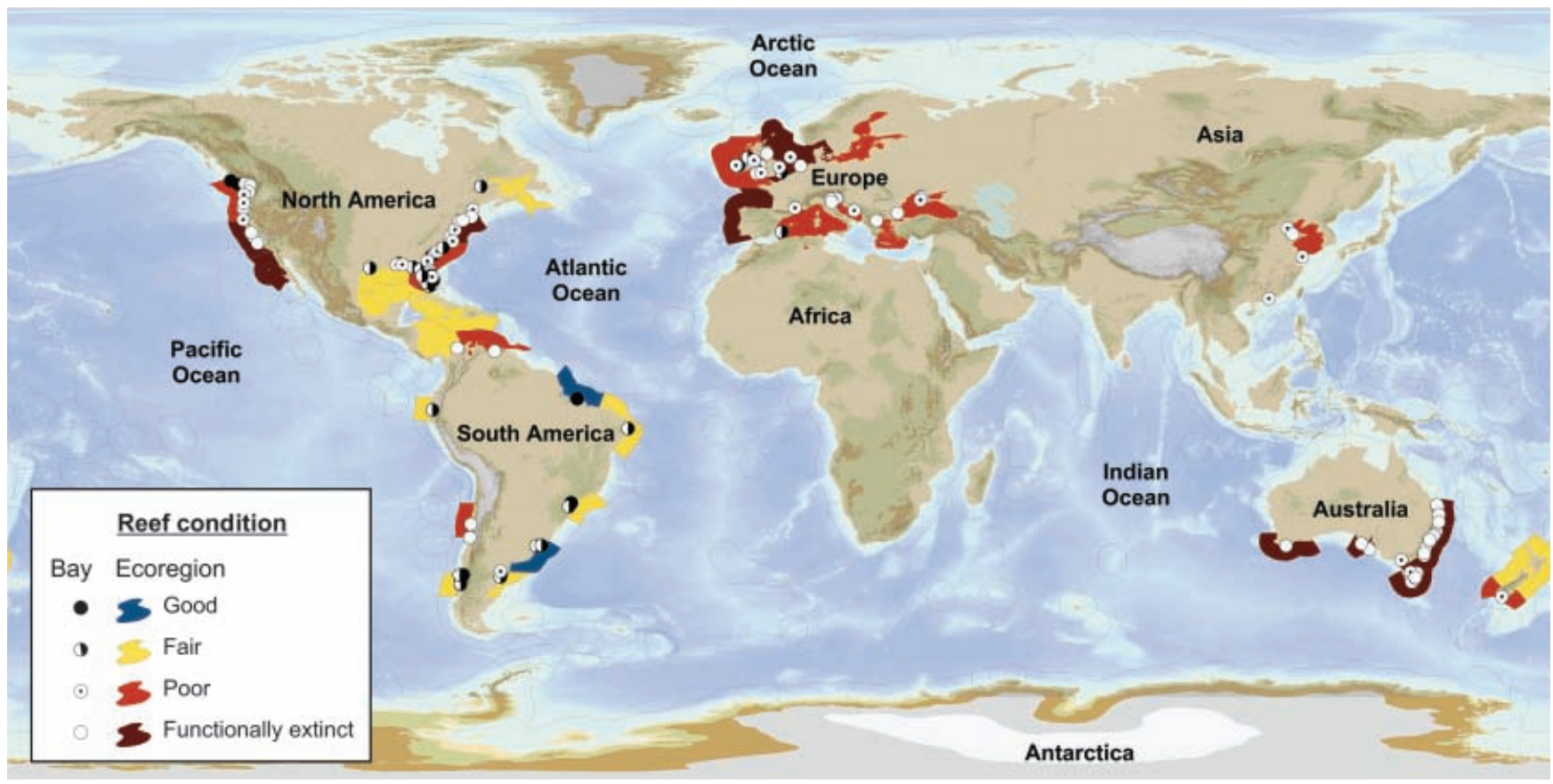

Figure 1. The global condition of oyster reefs in bays and ecoregions. The condition ratings of good, fair, poor, and functionally extinct are based on the percentage of current to historical abundance of oyster reefs remaining: less than 50\% lost (good), 50\% to 89\% lost (fair), 90\% to 99\% lost (poor), more than $99 \%$ lost (functionally extinct). Ecoregion boundaries are from Spalding and colleagues (2007). Not all regions with oysters could be assessed because of a lack of data (see text).

frequent evidence that restrictions had been placed on harvests and of concerns about the incidence of disease and environmental degradation, but in the great majority of cases, harvests continued until oysters could no longer be fished commercially (MacKenzie et al. 1997a, 1997b, NRC 2004).

The decline of oyster fisheries follows a common sequence of events in many places globally (MacKenzie et al. 1997a, 1997b, NRC 2004). Typically, the extensive harvest of wild oyster populations results in the loss of reef structure. Most declines start with the loss of vertical relief and complexity, often as a result of dredging and trawling, which exacerbates the impact of additional stresses from anoxia, sedimentation, disease, and nonnative species (Lenihan and Peterson 1998, 2004, Lenihan 1999, Lenihan et al. 1999). In many cases, years of declining harvest are followed by introductions of nonnative oysters that are released directly into the wild or that escape from nearby aquaculture (Ruesink et al. 2005). Overharvest and disease often lead to a population crash. Although oyster diseases occur in native populations, in many places the incidence of disease is associated with transfers of nonnative oysters for aquaculture and from ballast waters (NRC 2004). Other anthropogenic factors such as alterations of shorelines; changes in freshwater inflows; and increased loadings of sediments, nutrients, and toxins also contribute to declines (NRC 2004). There are few if any bays where only one stressor has affected oyster reefs.

\section{Wild fisheries and remaining reefs}

To compare present-day levels of wild oyster harvest among ecoregions, we used global commercial catch data developed by the Sea Around Us Project (Watson et al. 2004). These catch data are primarily based on the national catch statistics compiled by the Food and Agriculture Organization, allocated to half-degree cells of latitude and longitude, and then summed by ecoregion. To account for annual variation in catches, we used the average catch in metric tons of native oysters per ecoregion from 1995 to 2004. The biomass estimates are based on numbers of oysters in their shells.

Most of the world's remaining wild capture of native oysters comes from just five ecoregions on the East and Gulf coasts of North America, which together account for more than $75 \%$ of the global catch (figure 2). Only 10 ecoregions in the world reported wild oyster capture rates of more than 1000 metric tons per year from 1995 to 2004; only six ecoregions have average captures above 5500 metric tons, and five of these are in eastern North America (Virginian to Southern Gulf of Mexico ecoregions). Although there is catch remaining in these six ecoregions, it is much lower than in the past. Indeed, in most of the bays ( 20 of 34 ) in these six ecoregions, there has been at least a $90 \%$ loss in oyster reefs; in some cases the loss has been more than $99 \%$. Therefore, the condition of the oyster reefs is poor or functionally extinct in these bays and regions, but oysters continue to be harvested. Contemporary native oyster catches in the Gulf of Mexico are the highest in the world, despite significant declines in abundance and reefs in numerous bays (e.g., figure 1, table S1). 


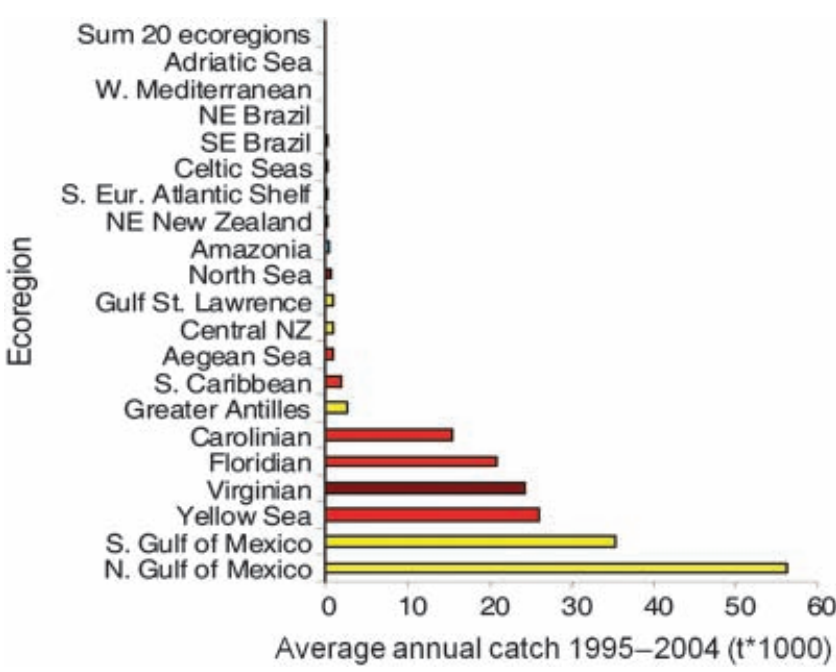

Figure 2. Average annual catch (thousands of metric tons) of wild harvested native oysters per year by ecoregion from 1995 to 2004. The colors of the bars correspond with the ecoregion condition in figure 1 . The top column is the sum of the average catch of the other 20 ecoregions for which reef condition was identified. For comparison, the peak harvest for many bays in the Virginian ecoregion occurred near 1890 at more than 800,000 metric tons.

\section{Regional data gaps}

We could not identify the condition of oyster reefs for several ecoregions, including parts of South Africa, China, Japan, and the Koreas. Research theses, anecdotal information, personal observations, and surveys of these areas suggest that wild oyster abundance was much higher in the past and that reefs have declined greatly in abundance or have disappeared altogether. There is no indication that the patterns of loss in data-poor areas are different from those in data-rich regions, or that filling the gaps in data would significantly change the global estimates of decline. However, there is not enough information for firm estimates of condition in these ecoregions.

The temperate areas of Asia pose special challenges for characterizing the status of oyster reefs, the greatest of which is that historical records for natural reefs are very poor. These regions, with about 20 recorded species (Guo et al. 1999), are at the epicenter of oyster diversity. Ancient reefs were widespread in these areas several thousand years ago. There have been significant losses of natural reefs, even in the past few decades, primarily from overfishing and habitat destruction. For example, there have been drastic recent declines in reefs in the Bohai Sea, such as the Hangu oyster reef, with $70 \%$ loss, and the Dajiawa oyster reef, with $90 \%$ loss (Fang et al. 2007).

Numerous factors contribute to the reef declines in temperate Asia, as exemplified by the Dajiawa reef. Overfishing was a major issue from the 1960 s to 1980 s as oysters were collected for food and lime. Direct habitat loss was also a significant problem as nearby cities expanded and reefs were demolished to provide access for commercial ships. Pollution from the chemical industries in the area caused further deterioration (Deng and Jin 2000), as did higher salinity as a result of reduced discharge from the Yellow and Liaohe rivers (Lin et al. 2001). Recently, the aquaculture of Crassostrea gigas has also caused major changes on the remaining Dajiawa oyster reefs.

The cultivation of oysters has been practiced for at least 2000 years in temperate Asia and has increased dramatically in recent decades (Guo et al. 1999). Present-day oyster production in this area comes from different forms of aquaculture that are based primarily on the collection of wild seed (Guo et al. 1999). The harvest of wild seed from reefs and the growth of oyster farms both have negatively affected natural reefs. Alternatively, some of the cultivation practices can provide limited reef habitat. For instance, oyster culture in southern Japan (Kyushu Island, Ariake Bay, and Shiranui Bay) involves the creation of managed shell "reefs" (C. gigas, Crassostrea sikamea, and Crassostrea ariakensis). In southern China (Guangxi and Fujian provinces), temporary structures placed on the bottom in intertidal habitats to collect spat somewhat resemble natural oyster reefs. In most areas with cultivation of C. gigas (Honshu, Japan; southern Korea; and northern China), Crassostrea angulata, C. ariakensis, and Crassostrea hongkongensis (central and southern China) oysters are suspended in the water column in a manner that does not mimic natural oyster habitat.

\section{Oyster reefs and ecosystem services}

Native oyster reefs provide many ecosystem services (figure 3 ) including water filtration, food and habitat for many animals (e.g., fish, crabs, birds), shoreline stabilization and coastal defense, and fisheries (reviewed in Grabowski and Peterson 2007, NRC 2010). For example, shellfish remove suspended solids from surrounding waters, thereby increasing water clarity (reviewed in Newell 2004), which can enable seagrass growth. The same filtration service can also reduce the likelihood of harmful algal blooms, which have important impacts ecologically and economically (Cerrato et al. 2004, Newell and Koch 2004). Shellfish can also help to remove excess nutrients from coastal bays by facilitating denitrification in surrounding sediments, which has tremendous economic value in areas where nutrient removal is a high priority for coastal policymakers (Newell et al. 2005).

Shellfish also serve as natural coastal buffers, absorbing wave energy directed at shorelines and reducing erosion caused by boat wakes, sea-level rise, and storms (Meyer 1997, Piazza et al. 2005). In addition, shellfish reefs play an important role as habitat for other species; fishes produced on oyster reefs have significant value to coastal economies (Grabowski and Peterson 2007). Lost habitat caused by declines in oyster reefs is also linked to broader drops in coastal biodiversity, which has both intrinsic and economic value (Lotze et al. 2006, Airoldi et al. 2008). Moreover, reef functions such as fish habitat and water filtration can enhance tourism and recreation by improving adjacent water quality 


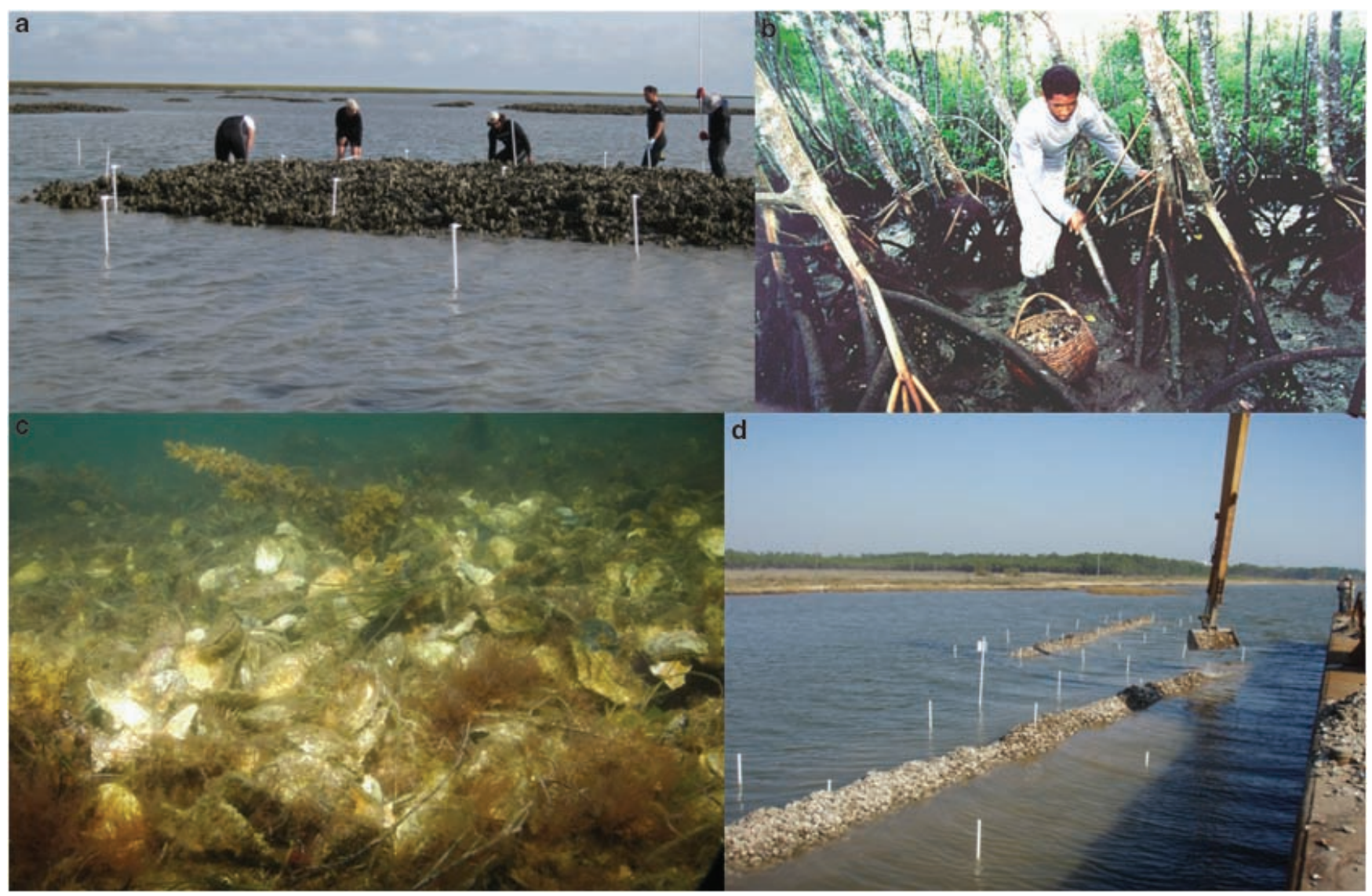

Figure 3. Oyster ecosystem services. (a) Light sensors deployed at low tide to measure filtration and changes in water clarity over a restored oyster reef in Virginia. (b) Oysters being gathered in a mangrove forest in Brazil. (c) Oyster reef restoration in progress to measure shoreline protection in Alabama. (d) Habitat provided by the Australian flat oyster in Tasmania, Australia. Photographs: (a) Robert Brumbaugh, (b) Marcelo Henriques, (c) Steven Scypher, (d) Graham Edgar.

and sport fisheries (e.g., Lipton 2004). Although there is increasing recognition that shellfish provide multiple ecosystem services, management for objectives beyond harvest has not yet become widespread.

Services from oyster reefs and oyster aquaculture recently have been examined extensively (Coen et al. 2007, NRC 2010). These services are well quantified compared with many other marine ecosystems and thus provide a real basis for estimating value lost to degradation and recovered through restoration. New decision-support models are being developed to help design restoration efforts that maximize ecosystem service benefits (North et al. 2010). A further step is to develop markets for these services; for example, credits for water filtration and denitrification from restored reefs could be bought and sold. Some nascent markets are being developed, but their expansion will require better quantification of ecosystem services (NRC 2010). In addition to ecosystem service markets, better valuations overall would allow managers and others to assess the true costs associated with the deterioration of natural oyster ecosystem services (NRC 2010). Such costs might then be recovered from those who degrade reefs intentionally.

\section{Toward improving condition}

Despite the continued decline of oyster reefs, their condition may be improved through conservation, restoration, and management of fisheries and nonnative species. Our analyses of reef condition help identify opportunities for improving reef abundance and condition. Many of the countries in which oyster reefs were most abundant have comparatively strong marine management regimes (Mora et al. 2009); this suggests a real, albeit unrealized, opportunity for reef recovery and conservation. New thinking and approaches are needed to ensure that oyster reefs are managed not only for fisheries production but also as fundamental ecological components of bays and coasts and for the return of other associated critical ecosystem services.

Shellfish reefs once dominated many of the temperate and subtropical estuaries on Earth. Recorded accounts indicate the existence of vast reefs with significant structural complexity in bays around the world. In many ways they were the temperate-climate equivalents of coral reefs, with large calcareous formations critical for creating habitat and maintaining biodiversity (Lenihan and Peterson 1998, Grabowski and Peterson 2007). Estimates of the 
loss of mangrove and saltmarsh $(30 \%-50 \%)$, seagrass (approximately 30\%), and coral reef (approximately 20\%) ecosystems have been influential in developing science and policy actions (Valiela et al. 2001, Wilkinson 2002, Zedler and Kercher 2005, Waycott et al. 2009, Spalding et al. 2010). Given the severity of oyster reef loss (85\%), the need for action is clearly urgent.

The devastation of shellfish reefs has been decades and centuries in the making, but this loss is not just a problem of the past. Oysters still are managed without regard for the structure or function of reefs. For example, in the 1990s, a wild remnant population of $O$. edulis in Greece collapsed from a combination of management lapses. That population declined from more than 1000 tons harvested to a point where it is now difficult to find 60 individual oysters (Virvilis and Angelidis 2006). Wild oyster populations in Strangford Lough (Northern Ireland) increased more than 10-fold from 1998 to 2002, most likely the result of a fortuitous broodstock sanctuary created by aquaculture. That recovery has been greatly slowed by subsequent unregulated harvest (Smyth et al. 2009). The only reefs of Ostrea angasi known to persist in Australia were recently reopened for commercial harvest in Georges Bay, Tasmania, without management consideration of their conservation significance as unique remnant reefs (ADEH 2004). The mangrove oyster, Crassostrea rhizophorae, vanished from the largest coastal Colombian Caribbean lagoon (Ciénaga Grande de Santa Marta) in 1996 as a result of the combined effects of overfishing and alterations in freshwater flow (Valero and Caballero 2003). A small population returned but was depleted by uncontrolled extraction in 2007. The few remnants of Olympia oyster beds in the US Pacific Northwest are still generally open for harvest. In the Chesapeake Bay, harvests continue at approximately $1 \%$ of their peak.

Reef conservation. Native oyster reefs should be recognized as an important habitat and ecosystem and a priority for habitat management and conservation. We have identified several areas with remaining reefs that are critical for conservation, including those bays with reefs in fair to good condition, particularly if these bays are in ecoregions with more than $90 \%$ reef loss overall (see figure 1, table S1). The need for action is pressing for flat oysters (Ostrea spp.) in Europe, Australia, and Pacific North America. For example, some of the last remaining reefs for these species occur in Georges Bay (Australia) and northwest Vancouver Island (Canada). In the Mediterranean Sea, Mar Menor (Spain) was considered to have one of the best-preserved natural beds of $O$. edulis, but its status has not been assessed since the mid-1990s (Ramón et al. 2005). Other areas where conservation opportunities should be explored in Europe include Scotland and Ireland, and the western part of the Swedish Kattegat region of the Baltic.

Protected areas have been used effectively for the conservation of coral reefs and other ecosystems. A few small, protected areas for oyster reef ecosystems have been established recently and are showing signs of success. For example, newly protected areas can be found in China (Jiangsu Province), the United States (North Carolina and Virginia), and Chile (Region X) (Peterson et al. 2003, Powers et al. 2009). These examples indicate that protected areas are useful tools for oyster reef conservation and should be expanded.

The extent of oyster reef habitat loss justifies more explicit recognition in protected areas policies. The European Union identifies biogenic reefs as a habitat for protection under Natura 2000. Although such recognition is encouraging, native oyster reefs of $O$. edulis should be clearly identified and elevated to a priority habitat type given their functional extinction throughout much of Europe. Oyster reefs should be specifically identified for protection under the Ramsar Convention; furthermore, they should be regarded with other similar wetlands (e.g., seagrasses, coral reefs, mangroves, kelp forests) as an "under-represented wetland type." International agencies and environmental organizations could bolster local efforts by adding temperate reefs to their conservation programs.

Oysters have been identified as a threatened or imperiled species and as a threatened and declining habitat by a number of countries in Northern Europe, around the Black Sea, in the United Kingdom, and elsewhere. The mangrove oyster is now included on the Venezuelan red list (Rodríguez and Rojas-Suárez 2003). On Canada, Ostrea conchaphila has been identified as a species at risk and a draft management plan is being developed (Gillespie 2009). Similar listings are appropriate in many regions and countries, including in the United States and Australia.

Fisheries management. The history of fisheries for native oysters has been almost universally one of unsustainable harvests, which are exacerbated by other stressors, including disease, sediments, pollution, and nonnative species, leading to population collapses (MacKenzie et al. 1997b, Lenihan et al. 1999, NRC 2004). Unfortunately, the pattern of continued harvest even as oyster populations and reefs collapse (from a variety of causes) is a persistent phenomenon globally. For many other fisheries, rebuilding plans are being developed, and there have been some important successes (Worm et al. 2009). However, plans for rebuilding oyster populations are rare. Where oyster populations constitute less than $10 \%$ of their prior abundances, we recommend no further reef destruction and the prohibition of harvests, unless it can shown that they do not substantially affect reef recovery. An important step in better fisheries management and reversing reef loss is the reduction of destructive harvest practices, mainly dredging, in favor of better alternatives (Lenihan and Peterson 2004).

Oyster fisheries in the Gulf of Mexico are probably the last remaining opportunity to achieve both large-scale oyster reef conservation and sustainable fisheries. While scientists and managers focus attention on relatively few well-known estuaries with oysters, such as the Chesapeake Bay (e.g., Jackson et al. 2001, Lotze et al. 2006), needs are not being met 
elsewhere and opportunities are being missed. There is a real opportunity for sustainable fisheries in the Gulf of Mexico, but even those reefs have been declining overall (figure 1 , table S1). To avoid the pattern of loss of most oyster fisheries and reefs around the world, more sustainable management actions are needed to ensure that harvests, particularly those carried out by dredging, do not damage the remaining reefs and that reef condition is monitored regularly.

To facilitate better management for sustainable fisheries and reef rebuilding, the distribution of reefs should be mapped. In many places the distribution of oyster habitat was better documented 100 years ago than it is today (e.g., Drake 1891). Nearshore habitat mapping, using, for example, side-scan sonar, multibeam sonar, and LIDAR (light detection and ranging), is now relatively cheap and widely available and provides a valuable tool in spatial planning for oyster reefs.

A foundation for better management of oyster reefs exists. Oysters have many of the elements that underpin successful efforts to sustainably manage other fisheries, including (a) the existence of extensive private rights, (b) populations that can be policed nearshore, and (c) clear links between the target species and ecosystem structure. Sustainable shellfish harvests have been achieved elsewhere through a mixture of protected areas for important populations, cooperative fishery management, user rights, and the use of aquaculture to reduce harvests of wild stocks. Indeed, institutional arrangements that provide for the comanagement of exploited oyster populations and the allocation of territorial user rights in fisheries (i.e., TURFs) help link sustainability and economic growth. These approaches include local fishers in land-use policy and management decisions and give them rights to manage biological resources. These catch share-based management approaches are being applied with success in artisanal benthic shellfisheries, including oyster and mussel fisheries, in South America (Castilla et al. 2007, Carranza et al. 2008, 2009).

Reef recovery and restoration. There have been some small- to medium-scale efforts to restore oyster habitats. Given the scale of losses, reef recovery and restoration efforts will need to be enhanced in many areas (figure 1). It is possible to achieve better returns on existing restoration investments, and new funding streams to rebuild services from reefs should become available (Coen et al. 2007).

Present funding for native oyster restoration is directed mainly at fishery enhancement and harm mitigation. In the United States, tens of millions of dollars have been spent in the past decade to recover fisheries (e.g., North Carolina, Chesapeake Bay, Delaware Bay) and to regain fishery production following hurricanes in the Gulf of Mexico. Often billed as restoration, the outcomes of these investments are measured mainly in near-term harvests; the other services provided by reefs are rarely measured. Indeed, if just the landings of other fish that use restored and protected reefs are considered, the habitat value of reefs can be greater than the oyster harvest value (Peterson et al. 2003, Grabowski and Peterson 2007). Assisting oyster fishers to overcome the effects of natural and human disasters and the legacy of poor management are important goals, but investment outcomes should be measured over the longer term (e.g., not just the put-and-take of oysters). Desired investment outcomes should include rebuilding the natural capital of reefs for long-term sustainable harvests and greater resilience to storms. Oyster managers and industry could play a central role in new restoration efforts. The recent British Petroleum Deepwater Horizon oil spill and the actions in response to it have already had major impacts on fisheries and oyster reefs, and there will be significant investments in response and restoration. These impacts and investments underscore the importance of reenvisioning our management and restoration approaches to support a sustainable future for both reefs and fishermen.

Improved recognition and measurement of the socioeconomic benefits from native reefs can create opportunities for new funding sources for restoration (Laing et al. 2006). As sea levels rise and the economic impacts of storms worsen, new funding should be generated for climate adaptation to restore oyster reefs for shoreline protection (Piazza et al. 2005). Markets are emerging for the trade of nitrogen pollution credits in coastal watersheds, and this approach has been used to fund the restoration of riverine buffers. Such markets might fund reef restoration if the nitrogen removal capacity of oyster reefs were harnessed appropriately. As this field of ecosystem services develops, we must take care to ensure that ecosystems and services are restored, not just the latter (Palmer and Filoso 2009). For example, nonnative species can help to restore some lost services but they cannot restore native habitats and ecosystems; when possible, both sets of management goals should be met. The idea that nonnative species and artificial structures can provide replacements for native species and natural habitats (NRC 2010) only partially addresses the recovery of ecosystem services and fails to promote precautionary management.

Managers should remove perverse incentives that hamper oyster reef recovery and restoration. There are real opportunities for conservation and restoration in areas where oyster harvest is limited by closures caused by poor water quality. Enhanced filtration by larger populations of native bivalves may even improve degraded waters. Conservation and restoration in these areas have sometimes been discouraged or disallowed because plentiful shellfish could entice illegal harvest. Leadership from the US Interstate Shellfish Sanitation Conference, among others, could help to identify solutions to this enforcement challenge and thus support enhancing shellfish abundance. Other disincentives to restoration should also be addressed, including the notion that restored reefs are navigation hazards, and the fact that planting shells in the water is sometimes regulated as ocean dumping or "fill."

Our results provide metrics (figure 1) with which reasonable goals for restoration and recovery can be identified, 
thus enhancing the chances for successful conservation and management. Realistic conservation goals include ensuring that abundances do not decline from one condition rank to the next. Restoration and recovery goals require raising reef abundance and condition to at least above $10 \%$ of historical levels. In bays where reef ecosystems have reached the point of functional extinction (figure 1), it is unrealistic to expect a fast recovery or quick returns on restoration investments, particularly while self-sustaining spawning stocks are rebuilt. Recovery actions and restoration investments should be made in bays and regions well before their condition slips from fair to poor (figure 1).

Although there have been only a few concerted efforts at oyster habitat restoration beyond small-scale projects, the groundwork for success has been laid. Some of the places where there have been initial successes in recovery and restoration include key areas within the Chesapeake Bay, Pamlico Sound (North Carolina), Strangford Lough (Northern Ireland), and Limfjord (Denmark), among others (Lenihan 1999, Brumbaugh et al. 2000, Laing et al. 2006, Brumbaugh and Coen 2009, Powers et al. 2009, Schulte et al. 2009, Smyth et al. 2009). Returns should accelerate greatly as reefs rebuild and become self-sustaining.

Nonnative species. Much of the spread of nonnative shellfish happened in the past, but they are still being spread today, intentionally and unintentionally, despite the many examples that demonstrate that introduced oysters and their hitchhiker species cause major ecological problems (Orensanz et al. 2002, NRC 2004, Ruesink et al. 2005, Molnar et al. 2008). Shellfish culture has been the second-greatest source of marine invasive species after ballast water (Molnar et al. 2008); these nonnatives include imported shellfish; their diseases; and many associated predators, competitors, and hitchhiker species (Ruesink et al. 2005, Molnar et al. 2008).

The International Council for the Exploration of the Sea (ICES) has developed codes of practice for marine introductions and transfers that should be followed in aquaculture to reduce the likelihood that new invaders are released into the wild (ICES 2004). These codes, however, do not address the fact that there are only a few regions without introduced oysters (Ruesink et al. 2005, Molnar et al. 2008), and they fail to consider the cumulative impacts of the global spread of a few oyster species with their hitchhikers and diseases. In consideration of these widespread geographical and ecological impacts, we recommend against further introductions.

Shellfish aquaculture has provided pressure to spread nonnatives, but aquaculture has also been a part of the solution in restoring native oyster reefs (Dumbauld et al. 2009). Shellfish aquaculture is more sustainable than most other forms of aquaculture (Naylor et al. 2000). Aquaculture can also reduce harvest pressure on wild shellfish populations when it is coupled with other capture fishery management tools (Castilla et al. 2007, Carranza et al. 2009). Aquaculture companies can play an even greater role in restoration given their expertise in oyster growing and oyster seed production. The aquaculture industry, public agencies, and environmental nongovernmental organizations are natural partners for promoting the restoration of native oysters and their services. Together, these groups could promote businesses to help produce native oyster species that can be sold for market while generating funds and seed oysters for habitat and population restoration.

There is also common ground among the aquaculture industry, environmental groups, and managers in conserving and restoring coastal water quality. Improved watershed management is critical in producing better overall estuarine condition, which in turn is vital for both shellfish aquaculture and effective management of natural reefs. Oysters are useful bioindicators for coastal condition and can be used to help target and monitor needed remediation actions in watershed management (Volety et al. 2009). Indeed, watershed management will prove to be one of the biggest challenges to conserving shellfish and other coastal ecosystems. The fate of oysters is tied to overall estuarine condition. Improving estuaries will require significant effort, especially because such efforts must be watershed based.

\section{Conclusions}

The condition of oyster reef ecosystems is poor and the challenge in revitalizing native oyster reefs is great, but we have identified many reasonable actions that can be expanded across local to regional to global scales. Actions recommended to reverse this decline and enhance oyster reef condition include improving protection; restoring ecosystems and ecosystem services; fishing sustainably; stopping the spread of nonnatives; and capitalizing on joint interests in conservation, management, and business to improve estuaries that support oysters. Estimates of oyster reef abundance and condition across many bays and ecoregions provide a baseline for setting much-needed and realistic goals for restoration and conservation and for evaluating the progress in meeting them.

Many obstacles hinder successful management of oyster reefs; one of the most pervasive is simply the perception among managers and stakeholders that no major problems exist (Laing et al. 2006). Recovery efforts are also hampered by the common misperceptions that shellfish habitats cannot be successfully recovered and that nonnative shellfish in aquaculture can replace natives. Put simply, native oysters must be recognized for the reef habitat that they provide. A growing number of examples demonstrate that recovery is feasible. We need new approaches within the regulatory and management communities to lead to shellfish habitat conservation and restoration designed not just for fisheries production but specifically to recover these critical ecosystems and their services.

\section{Acknowledgments}

This work was funded by the Kabcenell Family Foundation, NOAA Restoration Center, AdriaBio (University of Bologna), and the Santa Barbara Coastal Long-Term Ecological Research 
program (NSF OCE-0620276). The authors thank Christine Shepard, Zach Ferdaña, Jeff Vincent, Antonella Fatone, and Bill Arnold for help with the data and Peter Kareiva, Lynne Hale, and David Strayer for thoughtful reviews of the manuscript. This is contribution no. 20 from the Sanibel-Captiva Conservation Foundation Marine Laboratory.

\section{References cited}

[ADEH] Australian Department of the Environment and Heritage. 2004. An Assessment of the Tasmanian Native Oyster Fishery. ADEH.

Airoldi L, Beck MW. 2007. Loss, status and trends for coastal marine habitats of Europe. Oceanography and Marine Biology: An Annual Review 45: 345-405.

Airoldi L, Balata D, Beck MW. 2008. The gray zone: Relationships between habitat loss and marine diversity and their applications in conservation. Journal of Experimental Marine Biology and Ecology 366: 8-15.

Brumbaugh RD, Coen LD. 2009. Contemporary approaches for smallscale oyster reef restoration to address substrate versus recruitment limitation: A review and comments relevant for the Olympia oyster, Ostrea lurida Carpenter 1864. Journal of Shellfish Research 28: 147-161.

Brumbaugh RD, Sorabella LA, García CO, Goldsborough WJ, Wesson JA. 2000. Making a case for community-based oyster restoration: An example from Chesapeake Bay. Journal of Shellfish Research 19: 467-472.

Carranza A, Defeo O, Beck MW. 2008. Diversity, conservation status and threats for native oysters (Ostreidae) in the Atlantic and Caribbean coasts of South America. Aquatic Conservation 19: 344-353.

Carranza A, Defeo O, Beck M, Castilla JC. 2009. Linking fisheries management and conservation in bioengineering species: The case of South American mussels (Mytilidae). Reviews in Fish Biology and Fisheries 19: 349-366.

Castilla JC, Gelcich S, Defeo O. 2007. Successes, lessons, and projections from experience in marine benthic invertebrate artisanal fisheries in Chile. Pages 25-42 in McClanahan TR, Castilla JC, eds. Fisheries Management: Progress towards Sustainability. Blackwell.

Cerrato RM, Caron DA, Lonsdale DJ, Rose JM, Schaffner RA. 2004. Effect of the northern quahog Mercenaria mercenaria on the development of blooms of the brown tide alga Aureococcus anophagefferens. Marine Ecology Progress Series 281: 93-108.

Coen LD, Brumbaugh RD, Bushek D, Grizzle R, Luckenbach MW, Posey MH, Powers SP, Tolley SG. 2007. Ecosystem services related to oyster restoration. Marine Ecology Progress Series 341: 303-307.

Deng J, Jin X. 2000. Study on fishery biodiversity and its conservation in Laizhou Bay and Yellow River estuary. Zoological Research 21: 76-82.

Doran E Jr. 1965. Shell roads in Texas. Geographical Review 55: 223-240.

Drake JC. 1891. On the sounds and estuaries of Georgia with reference to oyster culture. US Coast and Geodetic Survey Bulletin 19: 179-209.

Dumbauld BR, Ruesink JL, Rumrill SS. 2009. The ecological role of bivalve shellfish aquaculture in the estuarine environment: A review with application to oyster and clam culture in West Coast (USA) estuaries. Aquaculture 290: 196-223.

Fang E, Li W, Yu J. 2007. Sustainable use of live oyster reef in Bohai Gulf. Modern Fisheries Information 22: 12-14.

Gillespie GE. 2009. Status of the Olympia oyster, Ostrea lurida Carpenter 1864, in British Columbia, Canada. Journal of Shellfish Research 28: 59-68.

Grabowski JH, Peterson CH. 2007. Restoring oyster reefs to recover ecosystem services. Pages 281-298 in Cuddington K, Byers J, Wilson W, Hastings A, eds. Ecosystem Engineers: Plants to Protists. Academic Press.

Guo X, Ford SE, Zhang F. 1999. Molluscan aquaculture in China. Journal of Shellfish Research 18: 19-31.

Halpern BS, et al. 2008. A global map of human impact on marine ecosystems. Science 319: 948-952.

[ICES] International Council for the Exploration of the Sea. 2004. ICES Code of Practice on the Introductions and Transfers of Marine
Organisms. ICES. (23 November 2010; www.ices.dk/reports/general/2004/ icescop2004.pdf)

Jackson JBC. 2001. What was natural in the coastal oceans? Proceedings of the National Academy of Sciences 98: 5411-5418.

Jackson JBC, et al. 2001. Historical overfishing and the recent collapse of coastal ecosystems. Science 293: 629-638.

Kirby MX. 2004. Fishing down the coast: Historical expansion and collapse of oyster fisheries along continental margins. Proceedings of the National Academy of Sciences 101: 13096-13099.

Laing I, Walker P, Areal F. 2006. Return of the native: Is European oyster (Ostrea edulis) stock restoration in the UK feasible? Aquatic Living Resources 19: 283-287.

Lenihan HS. 1999. Physical-biological coupling on oyster reefs: How habitat structure influences individual performance. Ecological Monographs 69: 251-275.

Lenihan HS, Peterson CH. 1998. How habitat degradation through fishery disturbance enhances impacts of hypoxia on oyster reefs. Ecological Applications 8: 128-140.

. 2004. Conserving oyster reef habitat by switching from dredging and tonging to diver-harvesting. Fishery Bulletin 102: 298-305.

Lenihan HS, Micheli F, Shelton SW, Peterson CH. 1999. How multiple environmental stresses influence parasitic infection of oysters. Limnology and Oceanography 44: 910-924.

Lin C, Su J, Xu B, Tang Q. 2001. Long-term variations of temperature and salinity of the Bohai Sea and their influence on its ecosystem. Progress in Oceanography 49: 7-19.

Lipton D. 2004. The value of improved water quality to Chesapeake Bay boaters. Marine Resource Economics 19: 265-270.

Lotze HK, Lenihan HS, Bourque BJ, Bradbury RH, Cooke RG, Kay MC, Kidwell SM, Kirby MX, Peterson CH, Jackson JBC. 2006. Depletion, degradation, and recovery potential of estuaries and coastal seas. Science 312: 1806-1809.

MacKenzie CL, Burrell VG Jr, Rosenfield A, Hobart WL. 1997a. The History, Present Condition and Future of the Molluscan Fisheries of North and Central America and Europe, vol. 1: Atlantic and Gulf Coasts. US Department of Commerce.

. 1997b. The History, Present Condition and Future of the Molluscan Fisheries of North and Central America and Europe, vol. 3: Europe. US Department of Commerce.

Meyer BL. 1997. Stabilization and erosion control value of oyster cultch for intertidal marsh. Restoration Ecology 5: 93-99.

Molnar JL, Gamboa RL, Revenga C, Spalding MD. 2008. Assessing the global threat of invasive species to marine biodiversity. Frontiers in Ecology and Environment 6: 485-492.

Mora C, Myers RA, Coll M, Libralato S, Pitcher TJ, Sumaila RU, Zeller D, Watson R, Gaston KJ, Worm B. 2009. Management effectiveness of the world's marine fisheries. PLoS Biology 7: e1000131.

Naylor RL, Goldburg RJ, Primavera JH, Kautsky N, Beveridge MCM, Clay J, Folke C, Lubchenco J, Mooney H, Troell M. 2000. Effect of aquaculture on world fish supplies. Nature 405: 1017-1024.

Newell RIE. 2004. Ecosystem influences of natural and cultivated populations of suspension-feeding bivalve mollusks: A review. Journal of Shellfish Research 23: 51-61.

Newell RIE, Koch EW. 2004. Modeling seagrass density and distribution in response to changes in turbidity stemming from bivalve filtration and seagrass sediment stabilization. Estuaries 27: 793-806.

Newell RIE, Fisher TR, Holyoke RR, Cornwell JC. 2005. Influence of eastern oysters on nitrogen and phosphorus regeneration in Chesapeake Bay, USA. Pages 93-120 in Dame RF, Olenin S, eds. The Comparative Roles of Suspension Feeders in Ecosystems. Springer.

North EW, King DM, Xu J, Hood RR, Newell RIE, Paynter KT, Kellogg ML, Liddel MK, Boesch DF. 2010. Linking optimization and ecological models in a decision support tool for oyster restoration and management. Ecological Applications 20: 851-866.

[NRC] National Research Council. 2004. Non-native Oysters in the Chesapeake Bay. National Academy Press. 
2010. Ecosystem Concepts for Sustainable Bivalve Mariculture. National Academy Press.

Ogburn DM, White I, McPhee DP. 2007. The disappearance of oyster reefs from eastern Australian estuaries-impact of colonial settlement or mudworm invasion? Coastal Management 35: 271-287.

Orensanz JM, et al. 2002. No longer the pristine confines of the world ocean: A survey of exotic marine species in the southwestern Atlantic. Biological Invasions 4: 115-143.

Palmer MA, Filoso S. 2009. Restoration of ecosystem services for environmental markets. Science 325: 575-576.

Peterson CH, Grabowski JH, Powers SP. 2003. Estimated enhancement of fish production resulting from restoring oyster reef habitat: Quantitative valuation. Marine Ecology Progress Series 264: 249-264.

Piazza BP, Banks PD, La Peyre MK. 2005. The potential for created oyster shell reefs as a sustainable shoreline protection strategy in Louisiana. Restoration Ecology 13: 499-506.

Powers SP, Peterson CH, Grabowski JH, Lenihan HS. 2009. Success of constructed oyster reefs in no-harvest sanctuaries: Implications for restoration. Marine Ecology Progress Series 389: 159-170.

Ramón M, Cano J, Peña JB, Campos MJ. 2005. Current status and perspectives of mollusc (bivalves and gastropods) culture in the Spanish Mediterranean. Boletin Instituto Español Oceanografia 21: 361-373.

Rodríguez J, Rojas-Suárez F. 2003. Libro Rojo de la Fauna Venezolana. PROVITA-Fundación Polar.

Ruesink JL, Lenihan HS, Trimble AC, Heiman KW, Micheli F, Byers JE, Kay MC. 2005. Introduction of non-native oysters: Ecosystem effects and restoration implications. Annual Review of Ecology Evolution and Systematics 36: 643-689.

Schulte DM, Burke RP, Lipcius RN. 2009. Unprecedented restoration of a native oyster metapopulation. Science 325: 1124-1128.

Smyth D, Roberts D, Browne L. 2009. Impacts of unregulated harvesting on a recovering stock of native oysters (Ostrea edulis). Marine Pollution Bulletin 58: 916-922.

Spalding MD, et al. 2007. Marine ecoregions of the world: A bioregionalization of coastal and shelf areas. BioScience 57: 573-583.

Spalding MD, Kainuma M, Collins L. 2010. World Atlas of Mangroves. Earthscan.

Valero AL, Caballero YQ. 2003. A Practitioner's Guide for the Culture of Marine Bivalves in the Colombian Caribbean Sea: Pearly Oysters, Oysters, and Scallops. Serie de Documentos Generales no. 10. Invemar Cargraphics.

Valiela I, Bowen JL, York JK. 2001. Mangrove forests: One of the world's threatened major tropical environments. BioScience 51: 807-815.

Virvilis C, Angelidis P. 2006. Presence of the parasite Marteilia sp. in the flat oyster (Ostrea edulis L.) in Greece. Aquaculture 259: 1-5.
Volety AK, Savarese M, Tolley SG, Arnold WS, Sime P, Goodman P, Chamberlain RH, Doering PH. 2009. Eastern oysters (Crassostrea virginica) as an indicator for restoration of Everglades ecosystems. Ecological Indicators 9: S120-S136.

Watson R, Kitchingman A, Gelchu A, Pauly D. 2004. Mapping global fisheries: Sharpening our focus. Fish and Fisheries 5: 168-177.

Waycott M, et al. 2009. Accelerating loss of seagrasses across the globe threatens coastal ecosystems. Proceedings of the National Academy of Sciences 106: 12377-12381.

Wilkinson C, ed. 2002. Status of Coral Reefs of the World: 2002. Australian Institute of Marine Science, Townsville, Australia.

Woods H, Hargis WJ Jr, Hershner CH, Mason P. 2005. Disappearance of the natural emergent 3-dimensional oyster reef system of the James River, Virginia, 1871-1948. Journal of Shellfish Research 24: 139-142.

Worm B, et al. 2009. Rebuilding global fisheries. Science 325: 578-585.

Zedler JB, Kercher S. 2005. Wetland resources: Status, trends, ecosystem services, and restorability. Annual Review of Environment and Resources 30: $39-74$.

Michael W. Beck (mbeck@tnc.org) is lead marine scientist with the Global Marine Team of The Nature Conservancy at the Institute of Marine Sciences, University of California, Santa Cruz. Robert D. Brumbaugh is a senior scientist with the Global Marine Team of The Nature Conservancy, in Summerland Key, Florida. Laura Airoldi is a researcher at Dipartimento di Biologia Evoluzionistica Sperimentale and Centro Interdipartimentale di Ricerca per le Scienze Ambientali, Università di Bologna, in Ravenna, Italy. Alvar Carranza is a graduate student and Omar Defeo is a professor at the Marine Science Unit, Ecology Department, Faculty of Sciences, in Montevideo, Uruguay. Loren D. Coen is director of the Sanibel-Captiva Conservation Foundation Marine Laboratory, in Sanibel, Florida. Christine Crawford is senior research fellow and Graham J. Edgar is associate professor at the Tasmanian Aquaculture and Fisheries Institute, at the University of Tasmania, in Hobart. Boze Hancock is a scientist with the Global Marine Team of The Nature Conservancy at the University of Rhode Island, in Narragansett. Matthew C. Kay is graduate student, and Hunter S. Lenihan is an associate professor, at the Bren School of Environmental Science and Management, at the University of California, Santa Barbara. Mark W. Luckenbach is a professor at the Virginia Institute of Marine Science, College of William and Mary, in Wachapreague, Virginia. Caitlyn L. Toropova is a program coordinator with the International Union for the Conservation of Nature, in Washington, DC. Guofan Zhang is a professor at the Institute of Oceanology, Chinese Academy of Sciences, in Qingdao, Shandong. Ximing Guo is a professor at the Haskin Shellfish Research Laboratory, at the Institute of Marine and Coastal Sciences, Rutgers University, in Port Norris, New Jersey. 